\title{
Nurturing the culture of student participation through online reflection using the QR code system
}

\author{
Mohd Fauzi Mohd Yunus ${ }^{1}$, Aspalilla Main ${ }^{2}$ \\ ${ }^{1}$ Politeknik Sultan Mizan Zainal Abidin, Jalan Paka 23000, Kuala Dungun, Terengganu, Malaysia \\ ${ }^{2}$ Politeknik Merlimau, KB1031 Pejabat Pos Merlimau, 77300 Merlimau, Melaka, Malaysia
}

\begin{tabular}{|c|c|}
\hline Article Info & ABSTRACT \\
\hline Article history: & \multirow{6}{*}{$\begin{array}{l}\text { Participation of student in reflection shows an important role in improving } \\
\text { learning strategies. However, the common reflection practice focuses only on } \\
\text { self-reflection and it becomes unauthentic. This innovation therefore attempted } \\
\text { to prepare the platform for student's reflection towards the teaching and } \\
\text { learning activities in class using online reflection system. Hence an online } \\
\text { reflection system based on QR code was developed to reflect this scenario. The } \\
\text { code successfully accesses the system and allow the written reflection. Testing } \\
\text { result shows the } 100 \% \text { efficiency of QR code recognition and excellence result } \\
\text { for inter-rater reliability analysis by experts respectively. }\end{array}$} \\
\hline Received Jan $12^{\text {th }}, 2020$ & \\
\hline Revised Feb $20^{\text {th }}, 2020$ & \\
\hline Accepted Mar $17^{\text {th }}, 2020$ & \\
\hline Keyword: & \\
\hline QR code & \\
\hline Reflection & \\
\hline
\end{tabular}

\section{Corresponding Author:}

Mohd Fauzi bin Mohd Yunus, Politeknik Sultan Mizan Zainal Abidin Email:mohd.fauzi@psmza.edu.my

\section{Introduction}

Developments in the field of information technology and communication give a significant influence in improving the quality of human life. In the era of revolution of the 4.0 industry that demands efficiency, digitalization, and automation, it provides a golden opportunity for those who are able to apply information and communication technology in various fields. This development proved to be the media introduction of the message of hope and human desire in the effort to realize the objectives and overcome the problems of various aspects of life without excluding the field of education (Syahri, 2017). In the field of education, the potential of information technology has been instrumental and continuously modernizing. This can be seen from the widespread access in obtaining the necessary information easily.

Reflection is a written record or feedback that is practiced in teaching and learning process after the process is completed. Many studies have shown that reflection plays an important role in helping to improve learning performance (Chen, Kinshuk, Wei, \& Liu, 2011). However, over the past decade, the reflection practice is focuses only on self-reflection that has been written in teaching preparation record. Therefore, it becomes inauthentic (Krutka, Bergman, Flores, Mason, \& Jack, 2014). Additionally, previous research indicates that teachers have difficulty in gaining the feedback and participation of students after the learning process is completed (Zembal-Saul, Blumenfeld, \&Krajcik, 2000). Therefore, an effective reflection tool needs to develop as a platform for students to engage in meaningful reflection. Besides, it was developed to cultivate and encourage the participation of students in giving the feedback to teachers in improving the learning performance and environment. 
With the rapid development of information technology at this time, computer use is expanding; likewise, with a cell phone that is increasingly sophisticated equipped with color, high resolution, access without wire and high-speed processing (Mohammad Hafiz, Z. \&Saedah, S. ,2017) ; (Rouillard, 2008).A mobile Tag is one way to expose the visual elements that the phone can identify,and tools simultaneously function with it. This two-dimensional barcode Bar can be found in any media printed or multi-item surfaces. It will work when users scan the code using the camera on the smartphone and the code will continue to display the scanned online information. This two-dimensional code Bar is better known as a QR code (Janssen, 2013).Based on Baik(2012), QR code used as a guide in getting to know the sign, helping to access the information of something object and also working to bypass a portal or information and be used in a variety of fields including logistics, management and so on. Although there are many advantages of QR code, but the user the field of education is still in the early stage (Latif et al., 2012).

Information technology has made the education process more effective and productive and hasincreased the well-being of students. Educational methods have been developed to make this processeasier, such as the replacement of paper with tablets. One well-known technology is the QR code

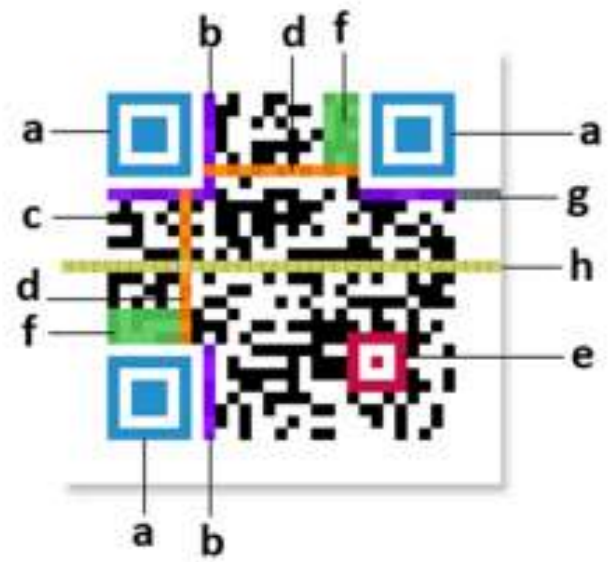

Figure 1: Anatomy of QR Code

According to Ariadi (2011), some explanation of anatomical QR Code among others: 1) Finder Pattern serves to identify the QR Code location; 2) Format Information works for information about error correction level and mask pattern; 3) Data serves to store encoded data; 4) Timing Pattern is a pattern that serves to identify the coordinates of the centerQR Code, black and white module; 5) Alignment Pattern is a pattern that works to improve irregularitiesQR Code is mainly nonlinear distortion; 6) Version Information is a version of a QR Code; 7) Quiet Zone is an empty area in the outermost part of QR Codeecognition by CCD sensors; 8) QR Code version is the version of the QR Code used.

Now, the use of the QR code is familiar in activities around the world, but this technology is stillunpopular and is not widely used in education. The QR code is being used to facilitate activities, suchas managing inventories, as these barcodes store specific data such as production codes, identificationnumbers and more, so that computer systems can easily identify the information encoded in barcodes. The QR code is a two-dimensional image of a data, especially text-shaped data, and it has evolvedfrom a one-dimensional to a two-dimensional barcode, whereby it is able to store much larger data.QR codes carry several hundred times more information than regular barcodes as they allowinformation to be stored both horizontally and vertically in a $2 \mathrm{D}$ barcode format. These codes can beread by dedicated readers or by using smartphones as long as they have a camera and an autofocusfeature. Also, the advantage of QR codes is that they can be easily created and printed using a regularprinter, thus making the process of physical distribution inexpensive. In fact, this process may beintegrated in the workflow of existing schedules.

\section{Method}

The purpose of this study is to identify about nurturing the culture of student participation through online reflection using the QR code system. To achieve this goal, this study is conducted qualitative in the form of analysis document. A few of previous survey report, conference proceeding, and journal had been referred as literature study, and analyzed with data gathered use schedule matric (Strauss \& Corbin, 1990). Document analysis is a systematic procedure for reviewing or evaluating documents - both printed and 
Nurturing the culture of student participation through online reflection using the QR code system

electronic (computer-based and Internet-transmitted) material. Like other analytical methods in qualitative research, document analysis requires that data be examined and interpreted in order to elicit meaning, gain understanding, and develop empirical knowledge (Corbin \& Strauss, 2008; see also Rapley, 2007).Apart from that, Onwuegbuzie et al. (2012) believe that variable related to the topic can be identified by doing research again towards literature study. This technique used, because it is method that is orderly to observe and evaluate document and electronic resource.

\section{Result and Discussion}

\section{Innovation development}

In this era, we live in a time of rapid technological, therefore it is important for the field of education to take an advantage and keep pace. Based on previous research, it is likely that the difficulties could be improved by combining the interest of students in gadget and technology to develop the reflection tool.Thus, a reflection online system based on QR code has been developed. It is combining the QR code as an interface to access to the online system for giving the feedback or reflection by students to their teachers. In order to access to the system, students are required to scan the QR code that attached to the attendance sheet by using their smartphone before they access the system and give the reflection (Figure 1). By end of the week, teachers are allowed to generate the recorded feedback from the students effectively. From the feedback and reflection, any improvement on learning strategies, activities and material can be made if any.

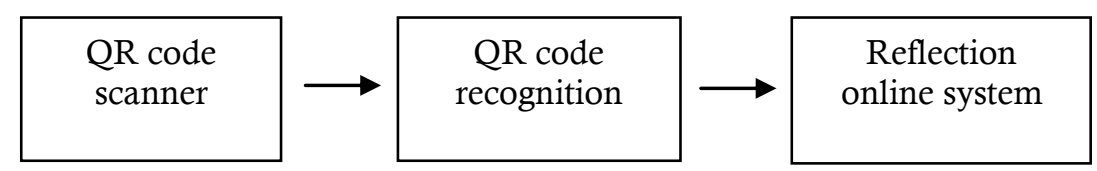

Figure 2: Process to access the reflection online system

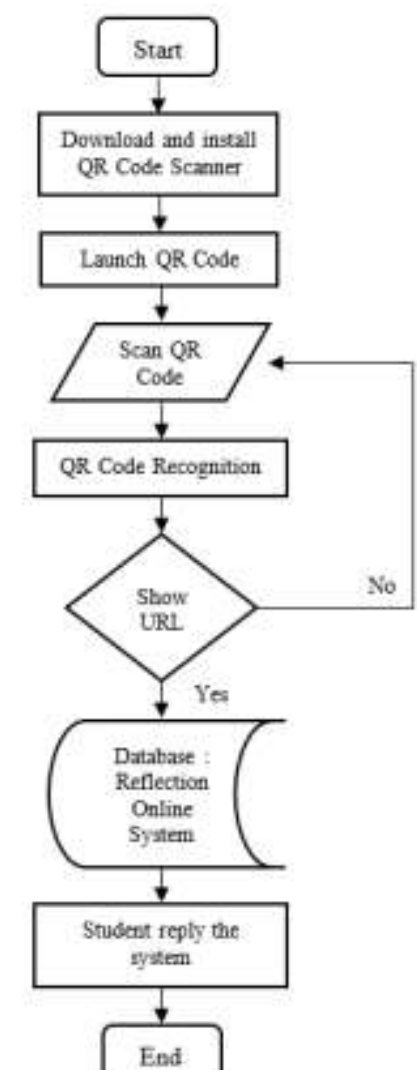

Figure 3: Flowchart of the QR Code Scanner

QR (quick response) code has been chosen as an interface to access the system based on the ability of $\mathrm{QR}$ code that is a fast, simple, accurate and automatic data collection method. It allows the product or system to be tracked efficiently and accurately at speeds which cannot be run by using the manual data entry (Liu, Yang, \& Liu, 2008). During recent years, implementation of QR code has been widely used and the capability of smartphone as a scanner of QR code became the trigger of the idea to develop this innovation. Besides, 
smartphones can implement various types of applications so the approach to capture the QR code with the camera to access into the system can be an attractive method to students to use the reflection tool.

Therefore, with the smartphone with camera device and QR code recognition, we developed a fast and efficient recognition in accessing a reflection online system to nurture the participation of students in giving the feedback to their teachers. Testing result shows the 100\% efficiency of QR code recognition and excellence result for inter-rater reliability analysis by experts respectively.

\section{Impact towards the education}

Many studies have shown that reflection can be an effective tool for improving learning strategies, as such this innovation enable to: 1) provide the reliable platform for reflection that align with the new technology ; 2) encourage students to give feedback to teachers through the use of technology (smartphone and QR code recognition and; 3 ) teachers can connect with the experiences and views of students to create new ideas or concepts for the next learning process.

This innovation and concept have the potential to be applied by various areas to provide a platform for gaining feedback and views in quick and efficient way. Indirectly, this innovation has the potential to cultivate and encourage people to give their views and reflections more transparent.Information Technology is a basic requirement in today's world. Technological progress is enteringall fields. Education is a big and important part of development and progress. The combination of education and technology is regarded as the main key to human progress.Education feeds technology, which in turn forms the basis of education. Therefore, it is evident thatinformation technology has brought about changes to the methods, purpose and perceived potential ofeducation.

\section{Conclusions}

Online Reflection gives you a good indication of how online learners progress and what they still need to do. However, self-assessments can draw their attention to personal areas of improvement so that they can search for online resources on their own. They also serve another important purpose, which is to reflect on the subject they have just learned and to assimilate the information (Mohammad Hafiz, Z. \&Saedah, S. ,2017).The caveat is that you must provide immediate feedback. For example, an online learner answers a question incorrectly. The system highlights the error, provides the correct response, and then offers supplemental online resources. The QR codes promote learning and information sharing, prepare young people for the future and provide teachers and students with resources that should not be lost but used to their full potentialTeodora Daniela, Essaid\&Monica, (2015). Just as students use technology to improve their learning process and success and encourage innovation, teachers should use technology to foster learning. The mobile device's portability and its ability to connect to the Internet from anywhere makes it an ideal repository for reference and learning experiences, as well as a common fieldwork tool where it can be used to record voice, text, or multimedia services, and reference resources for real-time access.

\section{References}

Baik, S. (2012). Rethinking QR code: analog portal to digital world. Multimedia Tools and Applications, 58(2), 427- 434

Chen, N. S., Kinshuk, Wei, C. W., \& Liu, C. C. (2011). Effects of matching teaching strategy to thinking style on learner's quality of reflection in an online learning environment. Computers and Education, 56(1), 53-64. http://doi.org/10.1016/j.compedu.2010.08.021

Krutka, D. G., Bergman, D. J., Flores, R., Mason, K., \& Jack, A. R. (2014). Microblogging about teaching: Nurturing participatory cultures through collaborative online reflection with pre-service teachers. Teaching and Teacher Education, 40, 83-93. http://doi.org/10.1016/j.tate.2014.02.002

Latif, L. A., Fadzil, M., Munira, T. A., \& Ng, M. S. (2011). Can The Use Of QR Codes Enhance M-Learning In A Blended Learning Environment?.Journal Lifelong Learning Society, 8(2), 1-20.

Liu, Y., Yang, J., \& Liu, M. (2008). Recognition of QR Code with mobile phones. In 2008 Chinese Control and Decision Conference (pp. 203-206). http://doi.org/10.1109/CCDC.2008.4597299

Mohammad Hafiz, Z. \&Saedah, S. (2017). KebolehlaksanaanPenggunaanKod Quick Response TerhadapPembelajaranHerba Kesihatan DalamKalanganPelajarInstitutPengajian Tinggi Di Malaysia. Jurnalkurikulum\&Pengajaran Asia Pasifik Vol. 4, No. 2 (2016), (pp.20-30)

Rouillard, J. (2008, July). Contextual QR codes. In The Third International Multi-Conference on Computing in theGlobal Information Technology, 2008. ICCGI'08 (pp. 50-55). Athens, Greece: IEEE. 
Nurturing the culture of student participation through online reflection using the QR code system

Teodora Daniela, C., Essaid, B. \& Monica, B (2015). QR Codes In Education - Success Or Failure?. In the 11th International Scientific Conference eLearning and Software for Education Bucharest, April 23-24 (pp. 180-187). http://doi.org/10.12753/2066-026X-15-208

Zembal-Saul, C., Blumenfeld, P., \&Krajcik, J. (2000). Influence of guided cycles of planning, teaching, and reflection on prospective elementary teachers' science content representations. Journal of Research in Science Teaching, 37(4), 318-339. http://doi.org/10.1002/(SICI)1098-2736(200004)37:4<318::AIDTEA3>3.0.CO;2-W 